\title{
AS PARTICULARIDADES JURÍDICA DA OCUPAÇÃO DO ESPAÇO URBANO DA CAPITAL DE UM JOVEM EX-TERRITÓRIO NA AMAZÔNIA OCIDENTAL: VIOLAÇÕES DE DIREITOS HUMANOS E RESISTÊNCIA
}

\author{
Rodolfo de Freitas Jacarandá ${ }^{1}$ \\ André Vilas Boas Gonçalves ${ }^{2}$ \\ Paloma Carvalho Lima ${ }^{3}$
}

\section{Resumo}

O trabalho analisa as formas de colonização da cidade de Porto Velho, a utilização do instituto da enfiteuse, a violação ao direito humano à moradia digna e propõe uma forma de defesa processual que privilegia a função social da propriedade. Utilizamos uma abordagem qualitativa, descritiva, com metodologia bibliográficadocumental. Pesquisamos também junto ao Sistema de Automação Processual do Tribunal de Justiça de Rondônia dados sobre o quantitativo de processos distribuídos que tratam de ações possessórias na cidade de Porto Velho nas Varas Cíveis entre os anos de 2000 a 2016. O trabalho aponta que a principal fonte de conflitos ligados às questões possessórias na cidade decorre da política frágil de colonização e desenvolvimento desenvolvidas. O crescimento demográfico na cidade foi impulsionado a cada ciclo econômico que a região experimentava. A oferta de moradia não acompanhou esse crescimento. $O$ déficit habitacional aliado a uma ausência de políticas públicas de regularização fundiária gerou uma ocupação irregular de grandes porções de terra por toda a cidade. As falhas de fiscalização pelos órgãos públicos no acompanhamento do uso que os foreiros faziam das porções de terra que recebiam refletem na insegurança jurídica e constantes conflitos até os dias atuais.

Palavras chave: Amazônia Ocidental; Moradia; Regularização Fundiária; Direitos Humanos.

\footnotetext{
${ }^{1}$ Doutor em Filosofia pela Universidade Estadual de Campinas - UNICAMP. Professor Adjunto da Universidade Federal de Rondônia. Coordenador do Programa de Mestrado Profissional em Direitos Humanos e Desenvolvimento da Justiça, da Universidade Federal de Rondônia - PPG/DHJUS.E-mail: rfjacaranda@uol.com.br

${ }^{2}$ Mestrando em Direitos Humanos e Desenvolvimento da Justiça pela Universidade Federal de Rondônia - PPG/DHJUS. Email: andre.dhjus@gmail.com

${ }^{3}$ Mestranda em Direitos Humanos e Desenvolvimento da Justiça pela Universidade Federal de Rondônia - PPG/DHJUS. E-mail: palomaclima@gmail.com
} 


\section{INTRODUÇÃO}

A colonização da região norte do país, notadamente a porção amazônica ocidental, possui certas peculiaridades em relação às demais. A utilização de instrumentos e políticas públicas para incentivar a colonização do espaço urbano de Porto Velho, jovem capital da Amazônia Ocidental, foi marcada pela grande concentração terras nas mãos de poucos beneficiários, distribuídas por meio da enfiteuse, que em sua grande maioria não deram destinação social à propriedade, relegando-as à inutilidade.

Após cada ciclo econômico que a cidade experimentava, o déficit habitacional aumentava, o que causou a ocupação dos espaços abandonados pelas pessoas que não tinham onde morar. A terras abandonadas com a demanda por espaço urbano resultou na criação de diversos assentamentos irregulares, com a ocupação dos lugares abandonados pelos senhorios. Com a valorização dessas áreas, o número de processos onde se busca o desalojamento dos ocupantes daquele imóvel causou uma corrida ao Judiciário.

O presente estudo analisa e aponta como possível origem dos problemas de moradia e assentamento irregulares formados na cidade de Porto Velho a má utilização dos imóveis que foram transferidos por meio da enfiteuse e que o enfiteuta não lhes empregou função social. As falhas de fiscalização pelos órgãos públicos no acompanhamento do uso que os foreiros faziam das porções de terra que recebiam refletem na insegurança jurídica e constantes conflitos até os dias atuais.

O trabalho ainda apresenta tese em defesa do direito fundamental à moradia digna: a alegação da perda da propriedade pelo enfiteuta pelo descumprimento das cláusulas compromissórias das cartas de aforamento, numa espécie de aplicação de pena de comisso como matéria de defesa. A propriedade na atualidade tem que ser entendida a partir da filtragem constitucional que a funcionalizou, erigindo o direito à moradia como fundamental.

Utiliza-se uma abordagem qualitativa, descritiva, com metodologia bibliográfica-documental. Pesquisouse também junto ao Sistema de Automação Processual do Tribunal de Justiça de Rondônia dados sobre o quantitativo de processos distribuídos que tratam de ações possessórias na cidade de Porto Velho nas Varas Cíveis entre os anos de 2000 a 2016.

\section{PROCESSO DE OCUPAÇÃO DO ESTADO DE RONDÔNIA}

Em um país de extensão territorial de aproximadamente $8.515 .767,049 \mathrm{~km}^{2}$ a preocupação com a manutenção de suas fronteiras é constante. No entanto, quando se olha para a história e se verifica o processo de formação do espaço territorial brasileiro, percebe-se que a região norte do país possui certas peculiaridades em relação às demais. Além do fator territorial, outro ponto importante a ser estudado são as consequências 
decorrentes das formas de ocupação, tanto para o espaço urbano quanto da perspectiva dos direitos humanos das pessoas diretamente envolvidas.

Dada a grande extensão territorial da região Amazônica, bem como a dificuldade de acesso, atreladas à pouca ou nenhuma tecnologia dos seus períodos de ocupação, um dos primeiros problemas que surgiram para fins de registro imobiliário e que ainda perduram, é a falta de delimitações precisas das propriedades de ocupação antiga. Além disso, sobrevieram outros problemas que culminaram com o maior da atualidade: a criação e consolidação de assentamentos irregulares por todas as cidades do estado em razão da ausência de políticas públicas de moradia e regularização fundiária.

Importante ressaltar que o direito humano diretamente envolvido neste estudo é o direito à moradia digna, que não diz respeito apenas a existência ou estrutura de uma residência, mas também a segurança jurídica do seu detentor em relação ao estado e a terceiros. $\mathrm{O}$ argumento jurídico eixo da relação da propriedade com o direito à moradia, é a função social dada àquela.

Desde o período posterior à ocupação portuguesa nas terras brasileiras, a região Amazônica, até então pertencente à Espanha, era objeto de invasão e exploração pelos bandeirantes portugueses, em busca em ouro, drogas do sertão e indígenas para serem escravizados.

Durante anos a região foi objeto puramente de exploração econômica, sem nenhuma intenção efetiva de povoamento. O cenário se alterou quando, no final do século XIX, movida pela Revolução Industrial, iniciou-se a exploração da borracha extraída das seringueiras amazônicas. Tal atividade econômica causou um verdadeiro surto de migração para a região, principalmente de nordestinos. Estima-se que entre 1870 e 1900 cerca de 300 mil pessoas chegaram na região (MOSER, CUNHA, 2010).

Essas pessoas não tinham direito a terras, vinham, principalmente, para o trabalho nos seringais. Esses seringais eram grandes latifúndios de propriedade dos barões da borracha.

As dificuldades atuais da regularização da moradia na cidade de Porto Velho são, em grande parte, reflexos de dois períodos cruciais da história brasileira e da ocupação da região: o do Governo do Presidente Getúlio Vagas (1930-1945) e o do Regime Militar (1964 - 1985).

\section{Governo Vargas}

A efetiva preocupação do governo brasileiro com a colonização da região amazônica apenas se deu no período em que Getúlio Vargas (1930-1945) assumiu a presidência, momento no qual a referida região passou a ser vista como estratégica para os interesses nacionais, tendo tal plano de governo sido denominado de 'Marcha para o Oeste'. 
O então Território Federal do Guaporé foi criado pelo Decreto no 5.812 de 13 de setembro de 1943, tendo sido constituído de áreas de terras desmembradas dos Estados do Amazonas e Mato Grosso. Também naquele ano se registra os primeiros incentivos específicos para a ocupação do recém-criado Território, época em que foi incentivada a ocupação efetiva por migrantes oriundos da região nordeste do Brasil.

Naquela época as terras do Território de Rondônia não despertavam interesse dos moradores de outras regiões do Brasil. Por muito tempo a atividade econômica predominante era o extrativismo vegetal da borracha e da castanha. A extração vegetal era realizada pelos nordestinos, que foram incentivados pelo Estado brasileiro a serem 'soldados da borracha'.

Durante esse período foi criado o Serviço de Patrimônio da União - SPU que, juntamente com o governo do território, até a promulgação do Estatuto da Terra (Lei no 4.504 de 30 de novembro de 1964), eram responsáveis pelas concessões de terras no Território Federal do Guaporé.

\section{Ditadura Militar}

Foi durante o período do Regime Militar no Brasil (1964 - 1985) que as ações voltadas para a ocupação estratégica efetiva e organizada da região amazônica foram colocadas em prática. Foi criado em 1967 o Grupo de Trabalho e Integração da Amazônia - GTINAM, que mais tarde veio a se tornar a Superintendência de Desenvolvimento da Amazônia - SUDAM.

Referido ente, conforme preleciona LIMA (1969, p. 24), tinha por finalidade precípua proceder com os estudos, sugerir medidas e adotar providências, tendo em vista definir e delimitar normas de execução da política objetiva do Governo Federal, no tocante a efetivação da ocupação e povoamento orientado da região amazônica, principalmente voltado para os espaços vazios e zonas de fronteiras. Como consequência dos referidos estudos surgiram projetos e medidas que propiciaram a vinda de colonos para a região.

Para Théry (2012), dentre os principais objetivos desses projetos estavam a transferência da problemática social e econômica das outras regiões brasileiras para a região amazônica.

O ponto de partida para a ocupação do atual espaço rondoniense, segundo COY (1988, p.171), foram as medidas e incentivos decorrentes do Programa de Integração Nacional - PIN, seguido pelos Projetos Integrados de Colonização - PICs, Projetos de Assentamento Dirigidos - PADs e Núcleos Urbanos de Apoio Rural - NUAR, todos esses estruturados em conjunto com a abertura de estradas e rodovias. O PIN, Decreto-lei n. 1.106 de junho de 1970, objetivava financiar a infraestrutura nas regiões de atuação da Superintendência do Desenvolvimento do Nordeste (SUDENE) e da Superintendência do Desenvolvimento da Amazônia (SUDAM). Por meio desse mecanismo, e para viabilizar a exploração e colonização das áreas próximas das 
rodovias federais, o governo federal criou, pelo Decreto-lei n.1.110 de 9 de julho de 1970, o Instituto Nacional de Colonização e Reforma Agrária (INCRA).

Entre 1970/76 o INCRA implantou 5 PIC (Projetos Integrados de Colonização) e 2 PAD (Projeto de Assentamento dirigido) em Rondônia. O tamanho dos lotes variava para cada modalidade de projeto. Nos PIC a área de cada lote era de 100 ha., padrão instituído para a produção agrícola familiar, enquanto nos PAD os lotes eram de 250, 500, 1000 ha., destinados às monoculturas como o cacau (Santos, 2001).

Os PIC's e PAD's faziam parte de um plano estratégico elaborado pelo Ministério da Agricultura para cumprir a reforma agrária proposta na lei 4.504 de 30 de novembro de 1964 (Estatuto da Terra). O primeiro PIC, em Ouro Preto, no distrito da Vila de Rondônia, então município de Porto Velho, foi criado ainda em 1970. Em 1980 mais de 380.00 pessoas haviam migrado para Rondônia, fazendo a população do Estado aumentar para mais de 500.000 habitantes.

Os Projetos Integrados de Colonização (PIC's), os Projetos de Assentamento Dirigidos (PAD's), os Projetos Fundiários (PF’s) e os Projetos de Assentamento Rápido (PAR's) elaborados e implantados pelo INCRA cobriram quase que integralmente os 24.294.400.0000ha pertencentes a extensão geográfica de Rondônia.

No começo da década de 80 os problemas da colonização em Rondônia começaram a se tornar destaque no cenário nacional. Para fazer frente a todos esses problemas foi criado em maio de 1981, pelo Decreto Federal no 86.029, o Programa de Desenvolvimento Integrado para o Noroeste do Brasil - POLONOROESTE. O Banco Mundial destinou para o período entre 1980 a 1985 para Rondônia um montante de aproximadamente 1 bilhão e 100 milhões de dólares (SANTOS, 2001; PRIETO, 2017).

Com o fraco desempenho do POLONOROESTE, em 1984 o programa sofre uma reformulação, com o intuito de arrumar as inconsistências entre o que havia sido estabelecido no plano e o que foi efetivamente implantado. Esse foi o período de consolidação das políticas de colonização.

No entanto, as primeiras dificuldades encontradas, com relação ao registro imobiliário à época, urbano ou rural, eram as divergências de limites nas fronteiras dos Estados do Amazonas e do Mato Grosso, o que acarretou conflitos com empresas privadas que alegavam ter a posse das referidas terras. Importante ressaltar que se utiliza o termo 'alegavam' uma vez que são grandes os indícios e era prática recorrente na época a realização de fraude da referida documentação. O objetivo era a apropriação indevida de terras públicas através da falsificação de documentos, por vários motivos, dentre eles a especulação imobiliária e venda dos recursos naturais do local (KOZEL \& SILVA, 2015). Tal prática era comumente chama da 'grilagem', uma vez que os falsificadores, com o intuito de dar um aspecto de originalidade aos documentos irregulares criados por eles, deixavam os papéis em gavetas com insetos, principalmente grilos, pois as fezes destes e outras intemperes atribuíam ao material uma 
coloração amarelada.

Apesar dessa prática fraudulenta o Estado brasileiro não cancelou a expedição de títulos provisórios e definitivos em favor de terceiros, o que acarretou, muitas vezes, na sobreposição de áreas, duplicidade de títulos e delimitação de terras. A título de exemplificação, algumas áreas eram muito maiores no papel do que de fato existiam, dificultando ainda mais o controle do estado sob a prática da grilagem.

A abertura de estradas foi um dos meios adotados pelo governo brasileiro para concretizar sua presença na região amazônica e posteriormente a sua colonização. Utilizava-se das verbas direcionadas pelo Fundo Monetário Internacional - FMI ao Programa Integrado de Desenvolvimento do Noroeste do Brasil POLONOROESTE. A principal obra desta época, dentro do território do atual Estado de Rondônia foi a construção (1968-1970) e pavimentação (1983) da rodovia BR-029, atual BR-364 (TEIXEIRA, DANTE, 1998; SANTOS, 2014).

A referida estrada usou como parâmetro o tracejado da linha telegráfica instalada pelo Marechal Candido Rondon, ligando Porto Velho ao restante do Brasil.

A abertura da referida rodovia fez Rondônia despertar para o resto do país como o novo Eldorado brasileiro, uma vez que facilitou o acesso de pessoas das demais regiões do Brasil para o local. Os migrantes seguiam pela estrada e quando conseguiam chegar ao seu destino ficavam acampados às margens da rodovia ou na cidade mais próxima esperando que seu nome fosse cadastrado e recebessem do recém-criado Instituto Nacional de Colonização e Reforma Agrária (INCRA) o seu pedaço de terra.

O INCRA foi uma das autarquias criadas pelo governo militar que tinha por objetivo ser executora tanto da política de desenvolvimento como da reforma agrária do país, tendo sido a agência que participou diretamente da distribuição e consolidação das terras de Rondônia. (KOZEL \& SILVA, 2015)

Concomitante ao incentivo de colonização na área rural do atual estado de Rondônia, no decorrer da década de 70, descobriu-se jazidas de cassiterita e ouro em diversas áreas do seu território, principalmente no eixo do Rio Madeira.

O governo federal, ainda na linha de manter seu domínio sob a região, intensificou o incentivo para a vinda da mão de obra para a atividade extrativista, passando a divulgar que na região amazônica estava sobrando emprego, minério e terra.

Movidos pela propaganda governamental, diversos migrantes, principalmente vindos dos estados do Maranhão, Pará e Ceará, se uniram aos migrantes sulistas e das demais regiões que não conseguiram suas terras junto ao INCRA encontraram na atividade extrativista no Rio Madeira um meio de vida e uma nova atividade econômica. Segundo SANTOS (2009), no auge da exploração garimpeira, na década de 80, no leito do rio, um dia de trabalho rendia cerca 1 quilograma de ouro, o que na cotação atual equivaleria a cerca de $\mathrm{R} \$ 9.000,00$ por 
dia.

O êxito na propaganda governamental se mostra no crescimento do número de migrantes entre os anos de 1977 a 1986, segundo dados da SEPLAN - Secretaria Estadual de Planejamento do Estado de Rondônia e CETREMI - Centro de Triagem e Encaminhamento de Migrantes - Vilhena/RO (CIM, 2003, p. 10):

\section{Evolução do total de migrantes cadastrados em rondônia}

\begin{tabular}{|c|c|}
\hline Ano & Migrante/população \\
\hline 1977 & 3.140 \\
\hline 1978 & 12.658 \\
\hline 1979 & 36.791 \\
\hline 1980 & 49.205 \\
\hline 1981 & 60.218 \\
\hline 1982 & 58.052 \\
\hline 1983 & 92.723 \\
\hline 1984 & 153.377 \\
\hline 1985 & 151.684 \\
\hline 1986 & 165.679 \\
\hline Total & 783.527 \\
\hline
\end{tabular}

Fonte: SEPLAN/RO; elaboração dos autores.

As consequências desse intenso fluxo migratório, que acabou por fugir do controle do poder público, desencadeou a formação de novas frentes de povoamento, ocasionando ocupações espontâneas e desorganizadas de terras da União. Já não bastassem os diversos conflitos no território rondoniense, ligados principalmente aos seringais, mineração, perda de terras pelos povos tradicionais e indígenas, o incentivo à migração para a região, surgia novo foco de conflito para as autoridades.

A venda de terras por particulares e representantes de companhia de colonização duvidosas enganavam os migrantes pouco instruídos, gerando conflitos violentos entre os novos e antigos ocupantes de terras.

O INCRA, em 1972, tentou intervir na situação, cadastrando os imóveis rurais, mas essa medida agravou ainda mais a situação ao gerar uma intensificação no fluxo migratório na década. A agência governamental não possuía estrutura para atender a grande quantidade de pessoas que chegavam a procura de lotes rurais.

Esses conflitos, atrelados às dificuldades encontradas pelos colonos, sendo a principal delas o fato que, apenas $17 \%$ das terras do hoje estado de Rondônia são propícias para a prática agrícola, agravaram a debandada de diversas pessoas da região, que acabaram por comercializar ou abandonar as propriedades e deslocar-se para outras áreas, gerando assim a concentração de terras.

O abandono dos seringais em virtude do fim do ciclo da borracha e da busca de melhores horizontes de trabalho abertos com a construção da BR-364 e possibilidade de possuírem pequenas propriedades nos projetos 
do governo, provocaram invasões desordenadas nas unidades de conservação, terras indígenas e as denominadas "terras sem dono" (KOZEL \& SILVA, 2015).

Verifica-se assim que, apesar do objetivo principal do governo brasileiro ao incentivar a ocupação da região amazônica ser o de minimizar ou extinguir conflitos nas regiões, Sul, Sudeste e Nordeste do país, o que ocorreu, em verdade, principalmente em decorrência da aplicação desordenada dos planos de ocupação e colonização do território rondoniense, foi uma simples transferência dos problemas das demais regiões para a primeira.

\section{REFLEXOS DO PROCESSO DE OCUPAÇÃO DA REGULARIZAÇÃO FUNDIÁRIA URBANA E RURAL}

Afim de facilitar o processo de urbanização das áreas das proximidades da faixa da atual BR-364, o governo federal, através da Lei no 6.431 de 11 de julho de 1977 doou aos municípios incluídos na região da Amazônia Legal, por onde passava a referida rodovia, as faixas de 100 quilômetros de terras de seus eixos, afim de que promovessem à expansão ou implantação de cidades, vilas e povoados, segundo o interesse das Administrações Municipais (Art. $\left.2^{\circ}\right)$.

Caso o município descumprisse a destinação prevista para as referidas áreas haveria a imediata revogação da doação $\left(\right.$ art. $\left.2^{\circ}, \mathbb{\$} 1^{\circ}\right)$, bem como deveria o referido ente ater-se também aos procedimentos licitatórios vigentes para a alienação.

Apesar do processo de venda ao terceiro ser feita pelo município, a responsabilidade de sua formalização era de um órgão federal. O título de domínio emitido, além de outros encargos também deveria prever, segundo a lei 6.431/77:

a) os requisitos a serem atendidos para que o município possa alienar, ou ceder, quando for o caso, lotes urbanos ou não, situados, na área doada, observadas as normas legais relativas às licitações ou a legislação federal pertinente à cessão de imóveis;

b) a exigência do cumprimento, no que for aplicável, da legislação federal, referente a loteamentos urbano e rural;

c) a existência de lei municipal que autorize a aceitação da doação onerosa.

A demarcação das terras sujeitas a doação era de responsabilidade, expressamente prevista na referida legislação, do INCRA ou outro órgão designado para este fim.

O INCRA utilizava como instrumento para a colonização das terras do atual estado de Rondônia o Contrato de Alienação de Terras Públicas (CATP), o Contrato de Concessão de Domínio de Terras Públicas 
(CCDTP), o Contrato de Promessa de Compra e Venda (CPCV), Títulos Definitivos (TD) nos Projetos de Colonização Oficial ou Assentamentos e os demais instrumentos ligados a regularização fundiária.

A legislação federal mencionada ainda previa expressamente, no seu artigo $5^{\circ}$, que a partir da emissão do título de domínio, as terras devolutas passariam a constituir patrimônio dos respectivos municípios, bem como os encargos delas decorrentes. O resultado foi que cerca de 93\% do território do Estado de Rondônia pertencia a União.

Tanto nas cartas de aforamento, melhor explicadas nos próximos tópicos, emitidas pela Prefeitura do Município de Porto Velho, quanto nos títulos emitidos pelo INCRA, possuíam a exigência de algumas contraprestações dos recebedores desses lotes, além da legalmente prevista, havia cláusulas resolutivas que impunham algumas obrigações aos cessionários ou assentados, que iam desde a o pagamento de determinada quantia referentes a taxas governamentais até o estabelecimento de efetiva residência ou a implementação de projetos de produção.

O que se viu, principalmente a partir da década de 1990, foi um abandono pelos recebedores das referidas áreas no entorno do município de Porto Velho, em decorrência da queda da produção aurífera na região e consequente desaquecimento da economia local.

Grande parte dos migrantes efetivamente se instalaram, sendo boa parte deles pessoas com parcos recursos financeiros, que não possuíam sequer um local para morar. Assim é que, a larga disponibilidade de terras devolutas ou desocupadas urbanas longe do centro das cidades, atrelado ao grande fluxo migratório gerado pelas políticas de colonização e ocupação do Estado anteriormente propaladas, importou em grandes ocupações. As ocupações consistem na instalação dos indivíduos e suas famílias nessas áreas de terras desocupadas tomando, efetivamente, posse das referidas terras e dando a elas destinação.

Essa forma de ocupação era dada de maneira desordenada e algumas vezes até incentivada por interesses políticos, especialmente com o intuito de obtenção de votos. Especuladores imobiliários também incentivavam as ocupações, pois mantinha várias áreas desocupadas nas proximidades das invasões e próximas às áreas centrais, com o intuito de promover especulação, pois a presença de habitantes no entorno de suas áreas obrigava o poder público a disponibilizar serviços básicos (pavimentação, água encanada, iluminação e outros).

O recente ciclo econômico decorrente do processo de construção, instalação e operação das UHE do Rio Madeira (2006 - 2016) escancarou ainda mais os problemas do processo de urbanização da cidade de Porto Velho.

O que se vê no judiciário é o impasse jurídico travado entre os proprietários com títulos outorgados pelo poder público, que nunca efetivamente tiveram posse de suas terras e por vezes sequer sabem os limites de suas propriedades e os efetivos ocupantes, que por anos estabeleceram na área sua moradia, fonte de renda e 
efetivamente ocuparam e desenvolveram a região. No atual momento, o que se questiona é a falta de comprovação ou mesmo descumprimento de alguma das cláusulas condicionantes estabelecidas nos títulos emitidos pelo poder público, por parte dos seus detentores, bem como a efetividade da posse pelos ocupantes e os limites das respectivas porções de terras de cada um destes.

\section{ENFITEUSE, AFORAMENTO OU EMPRAZAMENTO}

A colonização do espaço urbano de Porto Velho, como já apresentado, foi marcada por particularidades essencialmente originárias do fato de se tratar de uma capital de um jovem ex-território fincado na Amazônia Ocidental. A partir da contextualização da colonização do estado e da cidade, é importante discorrer sobre os institutos jurídicos que disciplinavam legalmente os títulos emitidos à época, como forma de outorga de propriedade.

A enfiteuse, o aforamento ou emprazamento, são tratados como sinônimos tanto pela doutrina quanto pelo Código Civil de 1916, que disciplinou a matéria.

PEREIRA (2007, p. 253) conceitua o instituto da seguinte forma: é um direito real e perpétuo de possuir usar e gozar de coisa alheia e de empregá-la na sua destinação natural sem lhe destruir a substância, mediante o pagamento de um foro anual invariável. A enfiteuse consiste, então, na transferência do domínio útil de uma propriedade, para outra pessoa, que passa a pagar, em razão disso, uma quantia anual chamada de foro. Há, então, o desmembramento da propriedade. Ao proprietário, ou senhorio direto, cabe o domínio direto. Ao enfiteuta, ou senhorio útil, cabe o domínio útil (HIRONAKA, 1998).

A transferência do domínio útil do senhorio direto para o foreiro deve ser perpétua. A perpetuidade é condição essencial para se caracterizar a enfiteuse, pois a sua ausência transformaria o ato em arrendamento ou locação.

A constituição de uma enfiteuse pode se dar por testamento ou por contrato, sendo essa a forma mais frequente. As partes têm plena liberdade para estipularem as cláusulas daquele contrato, como a necessidade de se dar função social à propriedade, desde que respeitados as exigências legais e os pressupostos básicos do instituto (sob pena de não os fazendo, desnaturar a enfiteuse em outro direito). É indispensável a inscrição, de quaisquer das formas de constituição, no registro de imóveis, sob pena de não o fazendo não constituir o direito real (PEREIRA, 2017, p. 271).

O aforamento somente pode incidir sobre terrenos incultos ou abandonados, a cuja utilização se destina, ou terrenos não edificados, mas destinados à construção, como um estímulo econômico a que se promova. Somente pode constituir enfiteuse o proprietário do imóvel - pessoa física ou jurídica - e, como modalidade de alienação, 
pressupõe a livre disposição dos bens, e exige outorga do outro cônjuge (PEREIRA, 2017, p. 259).

O Código Civil de 2002 extinguiu esse direito real, proibindo a constituição de novas enfiteuses ou de subenfiteuses. $\mathrm{O}$ mesmo artigo 2.038 disse ainda que enquanto existirem, as enfiteuses serão regidas pelas disposições do Código Civil de 1916. O parágrafo segundo desse artigo criou a exceção de que a enfiteuse dos terrenos de marinha se regularia por legislação especial (Decreto-Lei 9.760/46 e Lei 9.636/98).

Por isso que se reconhece a existência de duas modalidades de enfiteuse: a civil e a administrativa. A enfiteuse civil é constituída sobre os bens particulares e dos bens públicos de domínio municipal. Essas modalidades são regidas e disciplinadas, em razão da regra de direito intertemporal do artigo 2.038 do Código Civil de 2002, pelos artigos 678 a 694 do Código Civil de 1916. A enfiteuse administrativa, ou especial, se constitui sobre os imóveis públicos dominiais (comumente sobre os bens móveis da união, como os terrenos da marinha e acrescidos) (COSTA, 2012, p.9).

Por todas essas características, a enfiteuse atribui ao enfiteuta uma condição jurídica análoga à de proprietário (PEREIRA, 2007, P. 258).

\section{Finalidade Colonizadora}

A finalidade da enfiteuse, aforamento ou aprazamento pode ser resumido da seguinte forma: promover a ocupação territorial, estimular a produção local e aumentar a renda do ente público com a cobrança do foro. Houve relativo sucesso do instituto. Em um país de extensões territoriais, as terras incultas e necessitadas de quem as fizesse produzir borbulhavam. Essa forma de exploração da terra foi responsável por urbanizar áreas afastadas dos grandes centros e por criar núcleos industriais em diversos pontos do país (HIRONAKA, 1998).

No passado a enfiteuse representou a solução de um problema social. Foi uma das primeiras formas de se atribuir fundos para quem desejasse trabalhar na terra (VENOSA, 2003, p. 379). Uma evidência da relevância social do instituto é o fato de que a lei de 1916 limitou as terras que poderiam ser objeto de enfiteuse: somente as terras não cultivadas e terrenos urbanos não edificados (VENOSA, 2003, p. 381). Essa delimitação de objetos constituíveis gerou como consequência a fixação do homem na terra, tornando-a produtiva.

Em Porto Velho, a utilização da enfiteuse para a colonização do espaço urbano foi marcante. E atendia a interesses imediatos de uma localidade da Amazônia Ocidental: promovia a ocupação territorial, estimulava a produção local e aumentava consideravelmente a renda pública em razão da cobrança do foro.

O instituto serviu no Brasil inteiro e foi usado para fomentar a urbanização e o crescimento das cidades. Os municípios, através de uma "carta de aforamento" entregavam a um particular um determinado terreno, exigindo, nos termos da lei, o pagamento de um valor anual chamado de "foro" junto com o IPTU, além incluir 
outras cláusulas, como a necessidade de dar destinação ao terreno em determinado prazo.

Quando esse particular quisesse alienar o seu domínio útil a terceiros, se o proprietário do imóvel não quisesse usar o seu direito de preferência, o alienante deveria pagar o laudêmio, no valor de 2,5\% ao senhorio direto do bem, numa espécie de compensação por ter aberto mão do seu direito de reaver o bem. O laudêmio é cobrado juntamente com o imposto de transmissão de bens imóveis (ITBI).

Mas sempre houveram críticos da utilidade e da justeza do instituto, segundo VENOSA (2003, p. 380):

É o mesmo Pontes (1971, v. 18:179) que criticou veementemente a manutenção da enfiteuse em nossa legislação: o código civil conserva a enfiteuse, que é um dos cânceres da economia nacional, fruto, em grande parte, de falsos títulos que, amparados pelos governos dóceis a exigências de poderosos, conseguiram incrustar-se nos registros de imóveis.

\section{Direitos e obrigações do foreiro}

O enfiteuta, titular do domínio útil da propriedade, tem direito a usar, gozar e dispor do bem. Ele pode alienar o bem, mas deve comunicar o senhorio para que esse possa exercer o seu direito de preferência. Quando o senhorio não faz uso do seu direito de preferência, tem direito a receber o laudêmio. O enfiteuta também goza do direito de preferencia caso o senhorio pretenda alienar o seu domínio direto.

Também tinha direito a constituir subenfiteuses, mas a constituição de novas subenfiteuses foi expressamente proibida pelo Código Civil de 2002.

O principal direito do enfiteuta é o de realizar o resgate da propriedade plena. Esse resgate pode ser realizado após 10 anos da constituição do aforamento e mediante o pagamento de um laudêmio e de 10 pensões anuais. O direito ao resgate é indisponível e qualquer disposição contratual em contrário será inválida.

O enfiteuta é obrigado a pagar o foro anual. Esse valor é estipulado no momento da constituição da enfiteuse. $\mathrm{O}$ não pagamento de 3 foros consecutivos importa na ocorrência do comisso, causa de extinção da enfiteuse.

Além das obrigações acima, tem o foreiro a obrigação de pagar os impostos e ônus reais que gravarem o imóvel, já que ele é quem usufrui da propriedade.

\section{Direitos e obrigações do senhorio}

O senhorio, como já afirmado, possui direito de preferência em caso de alienação do bem pelo foreiro. Quando ele não utiliza o seu direito de preferência, ele é indenizado e faz jus ao recebimento do laudêmio, uma forma de indenização pelo não exercício do seu direito de preempção. 
O outro direito que o senhorio tem é o de receber o foro anual. Em caso de penhora do bem, ele terá direito de preferência em caso de arrematação, com iguais condições com os demais ofertantes. Em caso de falta de propostas, poderá adjudicar o bem, pagando o preço da avaliação.

\section{Extinção da enfiteuse}

A extinção da enfiteuse veio disciplinada genericamente no artigo 692 do Código Civil de 1916. Apesar do seu traço de perpetuidade, essencial para a caracterização do instituto, a enfiteuse pode ser extinta em algumas hipóteses: por abandono voluntário e gratuito, pelo foreiro, em favor do diretário; por natural deterioração do prédio aforado; pelo comisso; e pelo falecimento do enfiteuta sem herdeiros.

A hipótese mais comum de extinção da enfiteuse é o comisso, que consiste no não pagamento por parte do foreiro do foro no período de 3 anos consecutivos. Como se trata de uma punição extremamente severa, a pena de comisso só pode ser aplicada judicialmente e ao foreiro é dado o direito de purgar a mora até a sentença.

Outra hipótese de extinção da enfiteuse é o descumprimento de alguma cláusula do contrato que instituiu o direito, tema que exploraremos profundamente nos próximos tópicos.

A enfiteuse caiu em desuso mesmo antes da vigência do novo Código Civil, em 2003 (que proibiu a instituição de novas enfiteuses ou subenfiteuses). O rareamento das terras desocupadas, únicas aptas ao aforamento, a desvalorização da moeda, a valorização das terras e a impossibilidade de se alterar o valor do foro são apontados como os principais motivos que colocaram a enfiteuse em esquecimento. Instrumentos jurídicos mais novos e aptos à nova realidade se colocaram à disposição das pessoas para resolver os problemas atuais.

\section{ÁREA PÚBLICA OU PRIVADA?}

A enfiteuse ou aforamento permite ao ente público atribuir a outrem (enfiteuta ou foreiro) o uso completo de imóvel, inclusive transmissão a terceiro, recebendo, em troca, um foro anual, certo e invariável.

Os bens públicos dominicais, aqueles que não estão sendo utilizados para nenhuma destinação pública (artigo 99 do Código Civil de 2002), podem ser objeto de enfiteuse.

A constituição de enfiteuse em terreno público coloca em evidência a divisão do domínio do bem. De um lado, o ente público continuará com o domínio direto do bem, ou nú-proprietário. De outro, o particular, enfiteuta, ficará com o domínio útil.

O que se observa, portanto, é o desdobramento da propriedade plena em duas outras espécies de direitos reais: o domínio direto, que pertence ao proprietário ou senhorio direto, e o domínio útil, que fica com o enfiteuta, 
foreiro ou senhorio útil. O senhorio direto tem a propriedade do imóvel aforado mas está afastado dele, não possuindo mais a posse direta. (HIRONAKA, 1998)

A divisão do domínio do bem permite reconhecer a possibilidade de usucapião do domínio útil quando o bem aforado for público. Haverá a mera substituição do enfiteuta, ou foreiro, sendo que o domínio direto do bem permanecerá com o ente público. Não haverá qualquer diminuição do patrimônio público. Essa possibilidade mantém o respeito à regra que veda a usucapião dos bens públicos. Esse posicionamento já é pacificamente aceito pela jurisprudência (REsp 575.572/RS, Rel. Ministra Nancy Andrighi, Terceira Turma, julgado em 06/09/2005, DJ 06/02/2006, p. 276).

A discussão sobre o cabimento da ação de usucapião em face do enfiteuta, foreiro ou senhorio útil existe porque muitos deles simplesmente abandonaram os imóveis sem lhes emprestar qualquer destinação. Com a demanda por moradia sempre crescente, os imóveis abandonados pelos foreiros passaram a ser alvo de ocupação por pessoas que procuravam lugares para morar. $\mathrm{O}$ crescimento populacional experimentado em Porto Velho, notável a cada ciclo econômico, não foi seguido pela oferta de moradia.

Com o advento de mais um ciclo econômico na cidade de Porto Velho (a construção e a operação de duas usinas hidrelétricas no Rio Madeira), antigos foreiros que abandonaram os imóveis recebidos iniciaram uma ofensiva contra os ocupantes daqueles imóveis na tentativa de operar no especulativo mercado imobiliário.

O número das ações de reintegração de posse distribuídas nas Vara Cíveis da cidade, no período de 2007 até 2016, cresceu exponencialmente. No período entre 01 de janeiro de 2000 a 31 de dezembro de 2006 tramitavam 17 ações (outras que já haviam sido encerradas não são computadas para este cálculo). Já no período de 01 de janeiro de 2007 a 31 de dezembro de 2016, tramitavam 3.625 processos (também consideradas apenas as ações em trâmite nesta data), segundo dados do Sistema de Automação Processual - SAP, responsável pelo controle do trâmite processual dentro do Poder Judiciário de Rondônia.

Os ocupantes dos imóveis passaram a ser citados para apresentarem defesa e, em alguns casos, houve o deferimento de tutelas de urgência, que determinou a imediata desocupação.

\section{Documentos públicos com condições não cumpridas, o que fazer?}

Como bem coloca Oliveira Ascensão, citado por FARIAS (2012, p. 308), o direito é uma realidade finalista, racionalmente ordenada a fins. A ordem jurídica não é causal, mas é normativamente ordenada para finalidades, sendo que o fim do direito é o bem comum. A ausência de finalidade provoca a perda da base de legitimidade substantiva do ordenamento. A admissão de usucapião do domínio útil do bem público aforado reafirma a necessidade de se efetivar, à luz do texto constitucional e da inteligência do código civil, a função social 
da propriedade.

Admite-se a ação de usucapião do ocupante do imóvel aforado em face do antigo enfiteuta, também há de ser admitida a alegação da usucapião como matéria de defesa em ações que reivindicam a posse do imóvel. Nesse caso, o juiz, ao reconhecer a ocorrência da usucapião, deverá julgar improcedente o pedido reivindicatório. Apesar das divergências sobre a eficácia da sentença que reconhece a usucapião e julga improcedente o pedido, a natureza dúplice dessa ação oferece tranquilidade para o ocupante daquele imóvel, já que pleito reivindicatório será julgado improcedente.

Outras matérias podem ser alegadas por quem ainda não tenha preenchido todos os requisitos para o seu reconhecimento.

A pena de comisso pela falta do pagamento do foro só pode ser reconhecida judicialmente, além de ser reconhecido ao foreiro o direito de purgar a mora. A legitimidade para requerer a desconstituição do foro em razão do comisso, com a consequente reversão, seria do ente que instituiu a enfiteuse. Mas o reconhecimento do seu inadimplemento pode ser feito na ação de reintegração de posse, graças ao seu caráter dúplice (o inadimplemento é facilmente comprovável a partir da emissão de certidões do ente que instituiu a enfiteuse, especialmente em função do princípio da publicidade e dos mecanismos da lei de acesso à informação - lei federal $12.527 / 11)$

Quando alega o inadimplemento do foro, o ocupante do imóvel tem a intenção de ver declarado que o antigo foreiro não pode reivindicar um bem quando o seu domínio útil já não é mais seu (numa defesa da boa-fé objetiva a exemplo da utilizada na hipótese da exceção do contrato não cumprido). Em razão do inadimplemento de sua obrigação que gera a extinção da enfiteuse pelo comisso, ele é incapaz de comprovar a sua posse anterior, pois virtualmente extinta pelo comisso e tampouco poderá comprovar a propriedade do bem (que justificaria o manejo de ação reinvindicatória). Portanto, o pedido de reintegração de posse intentado contra o ocupante deverá ser julgado improcedente, mas sem a aplicação de penalidade pelo ente instituidor de reversão do bem.

A outorga de um bem público em razão de uma carta de aforamento, ou enfiteuse, pode vir gravada de outras obrigações ao senhorio útil além do pagamento do foro. Em razão da finalidade colonizadora do instituto da enfiteuse, é possível que no ato jurídico de concessão dos terrenos públicos para os particulares exista uma obrigação para de tornar a terra produtiva ou edificá-la em determinado espaço de tempo.

A Lei Municipal 202, de 12 de junho de 1981 tratou da matéria na cidade de Porto Velho. Dentre as suas particularidades, que fogem à regra geral do código civil de 1916, ela diz em seu artigo 14 quais são as causas de extinção do aforamento e aponta a possibilidade de extinção em virtude do descumprimento das cláusulas contratuais. Portanto, a não ocupação do terreno recebido com a devida destinação é causa de extinção do aforamento. A título de exemplo, a Carta de Aforamento 4554, expedida em 18 de fevereiro de 1963, elenca em 
sua cláusula quarta as obrigações daquele que recebe o terreno:

a tornar útil o terreno do lote aforado, cercando-o no prazo de seis meses, da data da concessão, edificando, em todo ou em parte, como for conveniente, fazendo-lhe qualquer outra sorte de benfeitorias, de modo a torna-lo proveitoso, no prazo de dois anos, bem como ceder para servidão pública, quando for necessário sem estrépito judicial, sem ônus ou qualquer embaraço, a quantidade de terreno precisa, salvo a indenização de benfeitorias úteis.

Mais a frente, na cláusula sexta, diz:

A sujeitar-se às penas de comisso e devolução à Prefeitura Municipal do lote de terras 3 aforado, na falta de pagamento do forro por dois anos consecutivos e na do cumprimento das clausulas acima e aqui estabelecidas, incorrendo, por cada ano que faltar ao pagamento dentro do prazo, na multa de $10 \%$ sobre o valor do mesmo lóte de terras.

É evidente que se o terreno foi ocupado por outras pessoas o foreiro não cumpriu suas obrigações de dar destinação ao imóvel. Nesse ponto é que se defende a possibilidade de alegar a extinção da enfiteuse pelo descumprimento da obrigação contratual de dar destinação ao imóvel.

O ocupante do imóvel que foi demandando em ação reivindicatória deverá alegar em sua contestação a ocorrência do descumprimento de condição contratual a fim de ver extinto quaisquer direitos do foreiro sobre o imóvel. Quando o foreiro não dá a devida e necessária utilidade ao bem aforado, ele também perde o domínio útil que recebeu.

Quando o descumprimento das regras impostas pelo antigo enfiteuta é alegado pelo ente que institui a enfiteuse, a consequência lógica é a resolutividade da enfiteuse com reversão do bem para o ente público, o que já é reconhecido em algumas decisões:

DIREITO CIVIL. ENFITEUSE. DISTRITO INDUSTRIAL. RESGATE. ALIENAÇÃO. ONUS REAL. CONDIÇÃO RESOLUTIVA. INADIMPLEMENTO. REVERSÃO AO ESTADO. RECURSO NÃO CONHECIDO.

Descumprindo o adquirente do bem enfiteutico resgatado a obrigação pactuada, enseja a ocorrência da condição resolutiva, a autorizar a reversão do domínio ao Estado.

(STJ - Quarta Turma - REsp 13.865/MG, Rel. Ministro Sálvio de Figueiredo Teixeira, em 24/2/1992).

DIREITO CIVIL. APELAÇÃO. AÇÃO DE REINTEGRAÇÃO DE POSSE. ESBULHO NÃO DEMONSTRADO. AFORAMENTO. ENFITEUSE. INADIMPLEMENTO CONTRATUAL. EXTINÇÃO LEGÍTIMA. NOVO AFORAMENTO. INTERESSE PÚBLICO. POSSIBILIDADE. IMPROVIMENTO.

I - Não dando o foreiro a devida e necessária utilidade ao imóvel aforado, a destituição da enfiteuse pelo ente político e a transmissão do domínio útil a outro pretendente afiguram-se legítimas, sobretudo quando há interesse público;

II - apesar de o senhorio direto não poder usufruir o bem e dele dispor convenientemente, cabe ao foreiro obedecer às condições prévia e conhecidamente entabuladas, sob pena de perder o domínio útil respectivo;

III - apelação não provida.

(TJ-MA - AC: 319682008 MA, Relator: CLEONES CARVALHO CUNHA, Data de Julgamento: 18/03/2009, URBANO SANTOS)

O que se defende neste trabalho é a possibilidade de o ocupante do imóvel alegar esse descumprimento 
como matéria de defesa (defesa processual ou indireta). Assim como a alegação de comisso, haveria o reconhecimento do descumprimento contratual, mas sem a aplicação de penalidade pelo ente instituidor de reversão do bem (único detentor de legitimidade para pleitear a extinção da enfiteuse).

Ressalte-se que a alegação de tais matérias não obsta ou gera litispendência para que o ente público que instituiu a enfiteuse postule a sua desconstituição judicialmente. A pessoa jurídica de direito público vai continuar na mesma situação em que estava antes, ou seja, de nu-proprietária. Nenhum prejuízo sofrerá.

As soluções apontadas aqui buscam responder aos questionamentos que batem às portas do sistema de justiça diuturnamente. Com a filtragem constitucional de todo o direito, sob o prisma da dignidade da pessoa humana, do reconhecimento do direito social à moradia, é necessário repensar o processo à luz do direito material. A falta de moradia assola diversas cidades do país. Movimentos sociais se organizam para lutarem por dignidade. Não se pode, com a chancela do poder judiciário, permitir que enfiteutas desidiosos sejam beneficiados pela sua inércia. A adoção dessa tese se funda na aplicação horizontal dos direitos fundamentais, como via de afirmação dos princípios constitucionais da função social da posse (art. 5 XXXIII, Constituição Federal) e do direito fundamental à moradia (artigo $6^{\circ}$, Constituição Federal), além do fato de ser o direito à moradia também um dos direitos humanos que o Brasil, como integrante da ONU e signatário do Pacto Internacional sobre os Direitos Econômicos, Sociais e Culturais (Decreto 591/1992), se comprometeu a zelar.

A resposta deve vir dotada de certo grau de ativismo (e não de politização judicial), colocando os valores que orientaram o Constituinte de 1988 em lugar privilegiado em relação ao direito do pacta sunt servanda.

\section{CONCLUSÃO}

A maioria dos conflitos ligados às questões possessórias na cidade de Porto Velho decorre da política frágil e mal estruturada de colonização e desenvolvimento da região, que acarretou a concentração de terras urbanas em mãos de poucos indivíduos que não ocuparam as terras que receberam.

O cenário da colonização da Amazônia ocidental brasileira é único. Diferentemente dos que aconteceu nos Estados Unidos, por exemplo, em que a colonização do oeste norte-americano se deu na superação de uma fase em que possuidores sustentavam direitos de facto até consolidar direitos de jure, mediados pelo estado; na Amazônia ocidental brasileira, seguidas campanhas em épocas diferentes, todas propostas pelo Governo Federal, provocaram a sucessão de sobreposições territoriais de direitos, alternando situações de jure sobre situações de jure (ALSTON, LIEBCAP, MULLER, 1999; 2012).

No caso da capital do estado de Rondônia, Porto Velho, embora sua origem date dos anos 1911, seu território jamais esteve bem delimitado - com as terras mais ao norte pertencendo, à época, ao estado do 
Amazonas, e ao sul, ao estado do Mato Grosso. Com o tempo, e após a criação do Território Federal do Guaporé, em 1946, o crescimento demográfico na cidade foi impulsionado a cada ciclo econômico que a região experimentava. A oferta de moradia, contudo, e a regularização fundiária não acompanhou esse crescimento. Isso gerou um déficit habitacional muito grande. Esse déficit, aliado a uma ausência de políticas públicas de regularização fundiária, gerou uma ocupação irregular de grandes porções de terra por todo o território da cidade, que abrange mais de 360 quilômetros de extensão. Houve falha na fiscalização dos órgãos públicos sobre o uso que os foreiros faziam das porções de terra que recebiam. Muitas destas propriedades serviam apenas à especulação imobiliária.

O ciclo econômico introduzido na cidade a partir da construção das das usinas hidrelétricas do Rio Madeira (2006-2016) fez aumentar o número de processos judiciais de reintegração de posse. Os antigos proprietários passaram a tentar reaver a posse da terra que perderam para aproveitar o crescimento do mercado imobiliário. Em razão do desconhecimento da história normativa da ocupação dessas terras e da falta de enforcement dos argumentos que visam a recompor os fundamentos jurídicos do mosaico da sobreposição irresponsável de direitos promovida pela desordem provocada pelo Governo Federal, o poder judiciário local não possui um entendimento harmônico sobre o destino a ser dado aos muitos territórios em disputa - cenário que se repete tanto nas cidades, como em Porto Velho, quanto na zona rural, onde os conflitos nos últimos anos transformaram o estado de Rondônia no local em que mais se mata no campo em todo o país (JACARANDÁ, MATZEMBACHER, 2018).

A resistência dos ocupantes de imóveis urbanos nas condições definidas acima que são demandados deve ser feita processualmente, alegando o perdimento da propriedade pelo descumprimento da cláusula obrigacional da carta de aforamento que exigia que o imóvel fosse destinado ao cumprimento de uma função social, numa espécie de aplicação da pena de comisso como matéria de defesa (processual indireta).

As terras repassadas ao particular por meio do instituto da enfiteuse só foram ocupadas porque a elas não foi dada função social. Eram improdutivas e abandonadas. A propriedade na atualidade tem que ser entendida a partir da filtragem constitucional que a funcionalizou, erigindo o direito à moradia digna como fundamental. 


\title{
THE PARTICULARITIES OF THE URBAN OCCUPATION OF A RECENT EX- TERRITORY IN THE WESTERN AMAZON: VIOLATIONS OF HUMAN RIGHTS AND RESISTANCE
}

\begin{abstract}
The paper analyzes the forms of colonization used in the city of Porto Velho, the use of the ENFITEUSE institute, the violation of the human right to decent housing, and proposes a way of procedural defense that favors the social function of property. A qualitative, descriptive approach is used with bibliographical-documentary methodology. It was also investigated with the Process Automation System of the Court of Rondônia data' on the quantitative of distributed processes that deal with possessory actions in the city of Porto Velho in the Civil Courts between the years of 2000 to 2016. The work points out that the main source of conflicts related to the possessory issues in the city derives from the fragile policy of colonization and development developed. Population growth in the city was boosted by every economic cycle the region experienced. The supply of housing did not follow this growth. The housing deficit coupled with an absence of public policies of land regularization led to an irregular occupation of large tracts of land throughout the city. The failures of inspection by the public agencies in the monitoring of the use that foreiros made of the portions of land that they receive reflects in the legal insecurity and constant conflicts until the present day.
\end{abstract}

Keywords: Western Amazon; Housing; Land regularization; Human rights.

\section{REFERÊNCIAS BIBLIOGRÁFICAS}

ALSTON, Lee J; LIBECAP, Gary D; MUELLER, Bernardo. Titles, Conflict, and Land Use: The Development of Property Rights and Land Reform on the Brazilian Amazon Frontier (Economics, Cognition, and Society). Michigan: Michigan University Press, 1999.

ALSTON, Lee; HARRIS, Edwyna; MUELLER, Bernardo. The Development of Property Rights on Frontiers: Endowments, Norms, and Politics. The Journal of Economic History, Vol. 72, No. 3 (September 2012). doi: 10.1017/S0022050712000356.2012. 
BBC. Brasília: BBC Brasil. Disponível https://www.bbc.com/portuguese/noticias/2009/07/090722_amazonia_timeline_fbdt\#ouronegro . Acesso em: 21 out. 2018.

BRASIL. Constituição Da República Federativa Do Brasil De 1988. Disponível em:

<http://www.planalto.gov.br/ccivil_03/Constituicao/Constitui\%C3\%A7ao.htm> Acesso em 18 jun. 2018.

Lei 10.416, de 10 de janeiro de 2002. Código Civil. Disponível em: < http://www.planalto.gov.br/ccivil_03/leis/2002/110406.htm>. Acesso em 24 jul. 2018.

Lei 3.071, de 01 de dezembro de 1916. Código Civil. Disponível em: <http://www.planalto.gov.br/ccivil_03/LEIS/L3071.htm>. Acesso em 21 jul. 2018.

Lei 6.431, de 11 de julho de 1977. Autoriza a doação de porções de terras devolutas a Municípios incluídos na região da Amazônia Legal, para os fins que especifica, e dá outras providências. Disponível em: <http://www.planalto.gov.br/ccivil_03/LEIS/L6431impressao.htm>. Acesso em 11 jul. 2018.

Decreto-Lei 9.760, de 05 de setembro de 1946. Dispõe sobre os bens imóveis da União e dá outras providências. Disponível em:

<http://www.planalto.gov.br/ccivil_03/decreto-lei/del9760.htm>. Acesso em 21 jul. 2018.

Decreto 59, de 06 de julho de 1992. Atos Internacionais. Pacto Internacional sobre Direitos Econômicos, Sociais e Culturais. Promulgação. Disponível em:

<http://www.planalto.gov.br/ccivil_03/decreto/1990-1994/D0591.htm>. Acesso em 03 set. 2018.

Lei 9.693, de 15 de maio de 1998. Dispõe sobre a regularização, administração, aforamento e alienação de bens imóveis de domínio da União, altera dispositivos dos Decretos-Leis nos 9.760, de 5 de setembro de 1946, e 2.398, de 21 de dezembro de 1987, regulamenta o $₫ 20$ do art. 49 do Ato das Disposições Constitucionais Transitórias, e dá outras providências. Disponível em: <http://www.planalto.gov.br/ccivil_03/LEIS/L3071.htm>.Acesso em 29 jul. 2018.

Lei 12.527, de 18 de setembro de 2011. Regula o acesso a informações previsto no inciso XXXIII do art. 5o, no inciso II do $\$ 3$ o do art. 37 e no $\$ 20$ do art. 216 da Constituição Federal; altera a Lei no 8.1 12, de 11 de dezembro de 1990; revoga a Lei no 11.111, de 5 de maio de 2005, e dispositivos da Lei no 8.159, de 8 de janeiro de 1991; e dá outras providências.. Disponível em: <http://www.planalto.gov.br/ccivil_03/_ato20112014/2011/lei/l12527.htm>. Acesso em 11 set. 2018.

Superior Tribunal de Justiça. REsp 575.572/RS, Relator: Ministra NANCY ANDRIGHI, Data de Julgamento: 06/09/2006, Terceira Turma, Data de Publicação: DJe

06/02/2006. Disponível em: <https://sti.jusbrasil.com.br/jurisprudencia/483930891/agravo-em-recurso- 
especial-aresp-532047-rj-2014-0148637-3>. Acesso em: 06 ago. 2018.

Superior Tribunal de Justiça. REsp 13..865/MG, Relator: Ministro Sálvio de Figueiredo Teixeira, Data de Julgamento: 18/12/1991, Quarta Turma, Data de Publicação: DJe
24/2/1992.
Disponível
em:

https://ww2.stj.jus.br/processo/ita/documento/mediado/?num_registro=199100173070\&dt_publicacao=24

-02-1992\&cod_tipo_documento=1\&formato=PDF >. Acesso em: 01 ago. 2018.

Tribunal de Justiça do Estado do Maranhão. AC 319682008, Relator: Cleones Carvalho Cunha, Data de Julgamento: 18/03/2009.

Disponível em: <https://www.jusbrasil.com.br/diarios/181110026/djma-09-03-2018-pg1793?ref=next_button>.Acesso em: 01 ago. 2018.

CIM, Salvador. O processo migratório de ocupação no estado de Rondônia - visão histórica. Porto Velho: Editora Universidade Federal de Rondônia, Centro de hermenêutica do presente, n¹04, 2003.

COSTA. Valestan Milhomem da. Enfiteuse - Aforamento ou Emprazamento. 1ª ed. São Paulo: IRIB, 2012.

DIÁRIO DO NORDESTE. Fortaleza: Diário do Nordeste. Disponível em http://diariodonordeste.verdesmares.com.br/cadernos/caderno-3/borracha-e-escravidao-nos-seringais-daamazonia-1.20521. Acesso em 15 jul. 2018.

FARIAS, Cristiano Chaves de. ROSENVALD, Nelson. Curso de direito civil. $8^{a}$ ed. Salvador: JusPodivm, 2012.

HIRONAKA, Giselda Maria Fernandes Novaes. Enfiteuse: instituto em extinção. Bauru: Revista do Instituto de Pesquisas e Estudos, n. 21, p. 37-47, abr./jul. 1998. Disponível em < http://bdjur.stj.jus.br/dspace/handle/2011/20124> Acesso em 18 jun. 2018.

IBGE. Rio de Janeiro: Instituto Brasileiro de Geografia e Estatística. Disponível em: https://agenciadenoticias.ibge.gov.br/2013-agencia-de-noticias/releases/14318-asi-ibge-apresenta-nova-areaterritorial-brasileira-8515767049-km.html. Acesso em: 15 ago. 2018.

KOZEL, S., \& SILVA, A. A. Ordenamento espacial em Rondônia: de território a estado. Terra Plural: Ponta Grossa, 2015, v. 9, p. 157-179. 
JACARANDÁ, Rodolfo. MATZEMBACHER, Priscila. Direitos humanos e o sistema de justiça nos conflitos de terra na Amazônia ocidental. Rev. Direito e Práx., Rio de Janeiro, Vol. 9, N. 1, 2018, p. 323-350. DOI: 10.1590/2179-8966/2018/32714| ISSN: 2179-8966

MOSER, Lilian Maria; CUNHA, Eliaquim Timotéo da. Os projetos de colonização em Rondônia. Revista Labirinto - Ano X, no 14 - dezembro de 2010.

NASCIMENTO, Cláudia Pinheiro. SANTOS, Carlos. SILVA, Maurício. Porto Velho: a produção do espaço urbano de Rondônia (1980/2010). Revista Geografar. Curitiba, v.7, n.1, p. 20-52 , 2012 ISSN: 1981-089X.

PICCINATO JUNIOR, Dirceu. Em chão urbano, o senhorio é santo: urbanização e aforamento de terras no bispado do Ribeirão Preto entre o Brasil Império e a Primeira República. 2016. 358 p. Monografia (PósGraduação em Urbanismo) - Pontifícia Universidade Católica De Campinas, Campinas, 2016. Disponível em: $<$ http://tede.bibliotecadigital.puc-

campinas.edu.br:8080/jspui/bitstream/tede/927/2/DIRCEU\%20PICCINATO\%20JUNIOR.pdf>. Acesso em: 12 set. 2018 .

PEREIRA, Caio Mário da Silva. Instituições de Direito Civil. 19ª ed. Rio de Janeiro: Forense, 2007.

PORTO VELHO. Prefeitura Municipal. Lei Municipal 202, de 12 jun. 1981. <https://leismunicipais.com.br/a/ro/p/porto-velho/lei-ordinaria/2008/178/1777/lei-ordinaria-n-1777-2008altera-o-disposto-na-lei-municipal-n-202-de-12-de-junho-de-1981-e-acresce-os-arts-14-a-14-b-14-c-14-d-e-14-ee-da-outras-providencias >.

PRIETO, Gustavo Francisco Teixeira. A aliança entre terra e capital na ditadura militar. Mercator, Fortaleza, v. 16, e16003, Fortaleza: 2017.

SANTOS, Alex Mota. Cartografias dos povos e das terras indígenas em Rondônia. Tese de doutorado. Universidade Federal do Paraná, 2014.

TEIXEIRA, Marco Antônio Domingues; FONSECA, Dante Ribeiro. História regional de Rondônia. Porto Velho: Rondoniana, 1998. 
THÉRY, Hervé, Rondônia mutações de um Território federal na Amazônia federal. Curitiba: SK Editora, 2012.

VENOSA, Sílvio de Salvo. Direito Civil. $3^{a}$ ed. São Paulo: Atlas, 2003.

Trabalho enviado em 29 de outubro de 2018

Aceito em 03 de novembro de 2018 